\title{
Médiévales
}

Langues, Textes, Histoire

69 | automne 2015

Travailler à Paris (XIIIe-XVIe siècle)

\section{Laurent FELLER, Le Meurtre de Charles le Bon, comte de Flandres (2 mars 1127)}

Paris, Perrin, 2012, 322 p.

Valérie Toureille

\section{OpenEdition}

Journals

Édition électronique

URL : https://journals.openedition.org/medievales/7655

DOI : 10.4000/medievales.7655

ISSN : $1777-5892$

Éditeur

Presses universitaires de Vincennes

Édition imprimée

Date de publication : 30 novembre 2015

Pagination : 205-206

ISBN : 978-2-84292-444-7

ISSN : 0751-2708

Référence électronique

Valérie Toureille, "Laurent feller, Le Meurtre de Charles le Bon, comte de Flandres (2 mars 1727)",

Médiévales [En ligne], 69 | automne 2015, mis en ligne le 12 décembre 2015, consulté le 23 avril 2022.

URL : http://journals.openedition.org/medievales/7655; DOI : https://doi.org/10.4000/medievales. 7655

Ce document a été généré automatiquement le 23 avril 2022.

Tous droits réservés 


\title{
Laurent FELLER, Le Meurtre de Charles le Bon, comte de Flandres (2 mars 1127)
}

Paris, Perrin, 2012, 322 p.

\author{
Valérie Toureille
}

\section{RÉFÉRENCE}

L. FELLER, Le Meurtre de Charles le Bon, comte de Flandres (2 mars 1127), Paris, Perrin, 2012, $322 \mathrm{p}$.

1 Dans cet ouvrage, Laurent Feller, plutôt familier des questions économiques et sociales, aborde un fait divers peu ordinaire, à la fois par les acteurs qu'il convoque, les modes opératoires mis en œuvre et les retombées politiques majeures induites. À travers ce titre, qui a reçu le prix de la Licorne en 2012, l'auteur nous offre une lecture neuve d'une histoire maintes fois rebattue: l'assassinat à Bruges du comte de Flandres, Charles le Bon, le 2 mars 1127. Les conditions mêmes du crime, au cours duquel le comte fut tué alors qu'il se trouvait en prières dans l'église Saint-Donatien, ont profondément marqué les esprits, par son caractère odieux mêlant le sacrilège et la trahison des vassaux. Cette affaire a inauguré une suite d'affrontements armés, dont le récit haut en couleurs méritait d'être rappelé. L'auteur le renouvelle au présent dans une langue fluide et agréable, en s'appuyant sur trois sources essentielles: celle de Galbert de Bruges, celle de Gautier, archidiacre de Thérouane, et celle de Hermann, chroniqueur de Saint-Martin de Tournai. De fait, la chronique du crime et de ses conséquences se lit comme une intrigue policière.

2 Les auteurs de ce crime hors normes, conduits par Borsiard, appartenaient tous à la famille des Erembald. Sans doute pensaient-ils, en faisant disparaître par l'épée tous les proches du comte, effacer les témoignages et bloquer les ressorts de la vengeance. C'est le contraire qui se produisit. Un chevalier de second rang ameuta des troupes dans l'intention de punir les coupables; il fut suivi aussitôt par la bourgeoisie urbaine qui s'arma dans le même dessein. Puis l'on vit les barons lever des hommes eux-aussi, et 
même les voisins des Brugeois, les bourgeois de Gand. Les Erembald semblaient craindre une disgrâce prochaine, prononcée par leur suzerain le comte, mais ils n'avaient pas anticipé la réaction de tous ceux qui ne souhaitaient pas leur donner raison. On découvre ainsi, au travers de ces évènements, le poids de la vengeance privée au $\mathrm{XII}^{\mathrm{e}}$ siècle, la force des clans nobiliaires, mais aussi la puissance d'une bourgeoisie urbaine qui n'entend pas être dépossédée de ses prérogatives politiques, tant à Bruges qu'à Gand. Sans doute lit-on aussi, en creux, l'opinion du petit peuple, car le comte Charles s'était fait la réputation d'un prince proche des pauvres, capable d'interdire en période de disette la fabrication de la bière pour que le grain pût servir au pain des plus démunis. Son assassinat en fit d'ailleurs une sorte de martyr.

3 La coalition des vengeurs eut tôt fait de contraindre le groupe des assassins à se réfugier dans le château comtal, avant de s'enfermer dans la tour, assiégé par une coalition improbable, réunissant chevaliers et bourgeois. Contrairement aux usages de la société féodale qui auraient dû prévaloir pour le règlement de ce conflit, ce ne fut pas la conciliation qui l'emporta, mais l'esprit de la vengeance, qui réclamait la mort des coupables. L'ultime intervenant de ce drame fut le roi de France lui-même, Louis vi le Gros, qui se chargea de déloger de leur réduit les derniers assiégés et désigna, en accord avec les barons, un nouveau comte de Flandres. En punissant les coupables, il accomplissait son devoir de suzerain. En n'autorisant pas les séditieux à contester la pyramide des pouvoirs, il condamnait le recours à la faide.

4 L'assassinat de Charles le Bon entraîna une série de conséquences que l'auteur explicite bien. Les riches villes flamandes profitèrent des troubles pour conforter face à l'aristocratie une reconnaissance de leur autonomie politique. D'une certaine façon, un nouveau rapport de pouvoir émergea qui allait préfigurer l'histoire des Flandres pour les siècles à venir. 